\title{
MORPHOLOGICAL AND PHYSIOLOGICAL CHANGES IN ESTERASE AND LIPID PEROXIDATION OF TWO BEAN CULTIVARS PRE-SOAKED WITH POTASSIUM NITRATE UNDER SALT STRESS
}

\author{
Mohamed A. K. Shaddad, ${ }^{1}$ Gaber K. Abd El-Baki, ${ }^{2 *}$ \\ Mostafa DoaA ${ }^{2}$ and Rafat Al-ShimaA ${ }^{2}$ \\ ${ }^{1}$ Botany Department, Faculty of Science, Assiut University, Assiut, 71515, Egypt \\ ${ }^{2}$ Botany and Microbiology Department, Faculty of Science, Minia University, El-Minia, 61519, Egypt
}

(Received: February 9, 2015; accepted: April 30, 2015)

Two broad bean cultivars (Vicia faba CV Nobaria3 and Vicia faba CV Sakha3) were obtained from Mallwi Agriculture Research Center, El Minia Governorate, Egypt. The seeds were divided into two groups, the first group soaked with distilled water, while the second group were soaked with $3 \mathrm{mM} \mathrm{KNO}_{3}$, respectively, for 4 hours. Seeds were sown and left to grow for 3 weeks then treated with different concentrations of $\mathrm{NaCl}(0.0,40,80,120$ and $160 \mathrm{mM})$ by top irrigation, then they left to grow further for 65 days from sowing. Plant samples were collected for some measurements: leaf area, plant height, root length, fresh and dry weight, photosynthetic pigments, carotenoids, soluble sugars, soluble proteins, total free amino acids, esterase enzyme, as well as MDA (malondialdehyde) content. Salinity reduced both fresh and dry weight in two broad bean cultivars, this reduction were more pronounced in Sakha3 than Nobaria3. Seed pre-soaking with $\mathrm{KNO}_{3}$ resulted in enhancement of fresh and dry weight production in both cultivars especially at $40 \mathrm{mM} \mathrm{NaCl}$. Photosynthetic pigments were substantially affected by salt treatment while the carotenoids were increased, seed pre-soaking with $\mathrm{KNO}_{3}$ improved these components. The soluble sugars, amino acids as well as soluble proteins showed various responses with increasing salinity in the cultivars, seed pre-soaking with $\mathrm{KNO}_{3}$ has improved these parameters to some extent. The shoots of two cultivars exhibited significant accumulation of MDA, compared to roots exposed to the highest salinity levels. Pre-soaking seeds with $\mathrm{KNO}_{3}$ did not improve MDA in shoots but enhanced it in roots, however, in most cases still lower than the absolute control. The assessment of the esterase isozyme profiles on $7.5 \%$ native polyacrylamide gel revealed the presence of 13 isoforms in two faba bean plants in response to $\mathrm{KNO}_{3}$ pre-soaking and treatments with different concentrations of $\mathrm{NaCl}$.

Keywords: Amino acids - chlorophylls - esterase enzyme - lipid peroxidation - salinity - Vicia faba

\section{INTRODUCTION}

Salinity is a major abiotic stress responsible for reduced crop production in many of the world. According to the FAO [17] it is expected that over 800 million ha will be affected by salinity in the near future, making it a major constraint to food production

Abbreviations: Carot. (carotenoids), Chl. (chlorophyll), cm (centimeter), EDTA (ethylene diaminetertaacetic acid), g (gram), LA (leaf area), MDA (malondialdehyde), TCA (trichloroacetic acid), WC (water content).

*Corresponding author; e-mail address: gaberahmed137@yahoo.com 
for a steadily increasing population. Salinity occurs mainly in arid and semi-arid regions, where evapotranspiration exceeds the annual precipitation. Currently, at least $20 \%$ of the world's irrigated land is salt-affected and/or irrigated with water containing elevated salt levels [40]. This increased salinization of arable land is expected to result in a $50 \%$ loss of arable land by the middle of the $21^{\text {st }}$ century [47]. Salinity is regarded as one of the major and increasing problems of the agricultural system in Egypt. The most important problems facing the economic crop production in arid and semi-arid regions are the high concentration of ions, especially $\mathrm{NaCl}$ that is present either in soil or water [34]. The adverse effects of high concentration of salts on plants are due to the osmotic retention of water and the specific ion effects on the protoplasm. Salt and osmotic stress are responsible for either inhibition or delayed seed germination and seedling establishment. Under these stress circumstances there is a decrease in water uptake during imbibition. Numerous attempts have been made to improve the salt tolerance of crops by traditional breeding programs, but commercial success has been very limited, pre-sowing seed treatment or seed priming is an easy technique, which improves seed performance and provides faster and synchronized germination used to overcome salinity problems [2]. Seed priming was defined as pre-sowing treatments in water or in an osmotic solution that allows seed to imbibe water to proceed to the first stage of germination, but prevents radical protrusion through the seed coat [32]. Pre-soaking or priming seeds of a number of crops has improved germination, seedling establishment and, in some cases, stimulated vegetative growth and so crop yield $[8,14]$. Seed priming enhance many of the metabolic processes involved with the early phases of germination, and it has been noted that seedlings from primed seeds emerge faster, grow more vigorously, and perform better in adverse conditions such as salinity, drought and temperature [2,5], it was also suggested that the adverse and depressive effects of salinity stress on germination can be alleviated by various seed priming treatments. It has been also demonstrated that this technique improves performance of plants and increased enzymatic antioxidants such as glutathione and ascorbate [25]. Cotton seed soaking in a solution of super phosphate increased the number of open boll. Similarly in wheat seed treated with a mixture of soluble salts with different concentrations of salinity significantly increased total chlorophyll, chlorophylls a and $\mathrm{b}$, and the ratio of chlorophylls $\mathrm{b}$ and a compared with untreated plants obtained from seeds [41]. Although the effect of priming treatments on germination of some seed crops have been studied, but relatively little information is available on the invigorating of faba bean seeds treated with $\mathrm{KNO}_{3}$ under salt stress. The aim of this study was to evaluate whether priming with $\mathrm{KNO}_{3}$ results in enhancement of seed vigor, growth parameters and yield in two broad bean cultivars (Vicia faba) CV Sakha3 and CV Nobaria3 under a range of osmotic potentials due to $\mathrm{NaCl}$. 


\section{MATERIALS AND METHODS}

Seeds of two broad bean cultivars (Vicia faba, CV Nobaria3 and CV Sakha3) were obtained from Mallwi Agriculture Research Center, El Minia Governorate, Egypt. They were selected for uniformity by choosing those of equal size and with the same color. The selected seeds were washed with distilled water, surface sterilized with $1 \%$ sodium hypochlorite solution for about 2 min and thoroughly washed again with distilled water. The seeds were divided into two groups, the first group soaked with distilled water, while the second were soaked with $3 \mathrm{mM} \mathrm{KNO}_{3}$ for 4 hours, then dried at room temperature $\left(25^{\circ} \mathrm{C}\right)$. Five uniform air dried faba bean seeds were sown along a centre row in each pot at $30 \mathrm{~mm}$ depth in plastic pots, each filled with about $4 \mathrm{~kg}$ mixed clay-sand soil ( 3 clay: 1 sand, $\mathrm{v}: \mathrm{v}$ ) in order to reduce compaction and improve drainage. Plants were left to grow for 3 weeks in open field and then treated with different concentrations of $\mathrm{NaCl}(0.0,40,80,120$ and $160 \mathrm{mM})$ by top irrigation, then left to grow further for 65 days after sowing. Plant samples (three replicates for each) were collected after 65 days from sowing for measurement of some growth parameters (i.e. leaf area, plant height, root length, fresh and dry weights of both shoots and roots), photosynthetic pigments, carotenoids, soluble sugars, soluble proteins, total free amino acids, and malondialdehyde (MDA) contents. Chlorophyll a, chlorophyll $\mathrm{b}$ and carotenoids were determined using a spectrophotometric method described by Metzner et al. [33]. Total free amino acids were determined according to the method of Moore and Stein [36], soluble sugars by anthrone sulphuric acid method which was carried out after Fales [16] and Schlegel [44] and adopted by Badour [4]. The soluble proteins were determined according to the method by Lowery et al. [31]. Leaf area measurements were carried out according to Wiersma and Bailey [48]. The level of lipid peroxidation was measured in terms of MDA content, as MDA is a product of lipid peroxidation following the method of Heath and Packer [24]. A leaf sample $(0.5 \mathrm{~g})$ was homogenized in $10 \mathrm{ml} \%$ trichloroacetic acid (TCA). The homogenate was centrifuged at $15,000 \mathrm{~g}$ for $10 \mathrm{~min}$. To $2.0 \mathrm{ml}$ aliquot of the supernatant, $4.0 \mathrm{ml} 0.5 \%$ thiobarbituric acid (TBA) in 20\% TCA was added. The mixture was heated at $95{ }^{\circ} \mathrm{C}$ for $30 \mathrm{~min}$, and then quickly cooled in an ice bath following by centrifugation at $10,000 \mathrm{~g}$ for $10 \mathrm{~min}$. The absorbance of supernatant was recorded at $532 \mathrm{~nm}$. The value for non-specific absorption at $600 \mathrm{~nm}$ was subtracted. The MDA content was calculated using its absorption coefficient of $155 \mathrm{n} \mathrm{mol}^{-1} \mathrm{~cm}^{-1}$ and expressed as $\mathrm{n} \mathrm{mol} \mathrm{g}^{-1} \mathrm{fw}$ (MDA). Preparation of polyacrylamide gel electrophoresis (PAGE) and staining of esterases, the plant tissue were homogenized in buffer (0.1 M Tris-HCl with $2 \mathrm{mM}$ EDTA pH 7.8) and centrifuged at 13,000 $\mathrm{g}$ for $15 \mathrm{~min}$. Esterase (EST, EC 3.1.1.x) isoforms were detected by staining with $\alpha$-naphthyl acetate/Fast blue RR according to Tanksley and Orton [46].

The data of all experiments were subjected to one-way analysis variance and means were compared using the least significant difference test (L.S.D.) using statistical program (Sta. Base. Exe.) on computer. 


\section{RESULTS}

Salinity reduced both fresh and dry weight of shoots and roots of cultavar Sakha3 at all salinity levels used except for $40 \mathrm{mM}$ which had a fresh weight higher than that of the absolute control $(0 \mathrm{mM} \mathrm{NaCl}), 103.4 \%, 106.7 \%$, respectively. Seed pre-soaking with $3 \mathrm{mM} \mathrm{KNO}$ had stimulatory effect on both parameters compared with reference control. This promoting effect which was more pronounced in roots than shoots and reached to $(167.5 \%)$ at $40 \mathrm{mM}$ compared with absolute control $(0 \mathrm{mM}$ $\mathrm{NaCl})$. The plant height and root length showed various responses with respect to salinity stress. Seed pre-soaking with $3 \mathrm{mM} \mathrm{KNO}_{3}$ decreased these parameters in shoots and increased them in roots especially at lower and moderate salinity levels used (Table 1).

Shoots and roots of CV Nobaria3 responded differently to salt stress, the shoots have decreased its fresh weight while the roots have increased fresh weight under the same conditions. Seed pre-soaking with $3 \mathrm{mM} \mathrm{KNO}_{3}$ had negligible effect on both fresh and dry weight production except for $40 \mathrm{mM}$ in shoots and $120 \mathrm{mM}$ in roots which had a stimulatory effect in both fresh and dry matter production over absolute control. Both shoot and root lengths showed a slight decrease with increasing salinity, seed pre-soaking with $\mathrm{KNO}_{3}$ had a positive effect in shoots than roots at almost all salinity levels used (Table 1).

The leaf area and water content of both cultivars are shown in Table 2. The data show that salinity reduced the leaf area in both cultivars, however, seed pre-soaking with $\mathrm{KNO}_{3}$ had a pronounced effect on leaf area at all salinity levels, especially in case of CV Sakha3. The water content in both shoots and roots of two cultivars had various responses, the roots had a higher water content than shoots at almost all salinity levels applied. It is worth to mention that CV Nobaria3 had the highest value of water content in both shoot and root compared to CV Sakha3. It was calculated as percentage of absolute control which could be used as a marker for conservation and utilization of water in that cultivar.

The pigment and carotenoid contents of both two cultivars are shown in Table 3. Both Chl. a and Chl. b had a slight increase with increasing salinity in the rooting medium. Seed pre-soaking of CV Nobaria3 had a remarkable increasing effect in both pigments as well as carotenoid contents. It is worth to mention that CV Nobaria3 had higher content total pigments and carotenoids than other cultivars, regardless the salinity levels used. The inhibitory effect of salt treatment on total pigments as well as carotenoids were only observed with $160 \mathrm{mM} \mathrm{NaCl}$ in CV Sakha3 pre-soaked with $\mathrm{KNO}_{3}$ which given $62 \%, 77.2 \%$ of absolute control, respectively.

The MDA and soluble sugar contents in both cultivars are presented in Table 4. The shoots of the two cultivars accumulated significantly higher MDA than roots at most salinity levels used. Additionally, salinity increased MDA contents in roots especially at lower doses (compared with absolute control). Seed pre-soaking with $\mathrm{KNO}_{3}$ resulted in accumulation of MDA in both organs (shoots and roots) at all salinity levels used. Sakha3 cultivar accumulated soluble sugars in both shoots and roots however, CV Nobaria3 accumulated sugars only at lower salinity levels in roots. Seed 


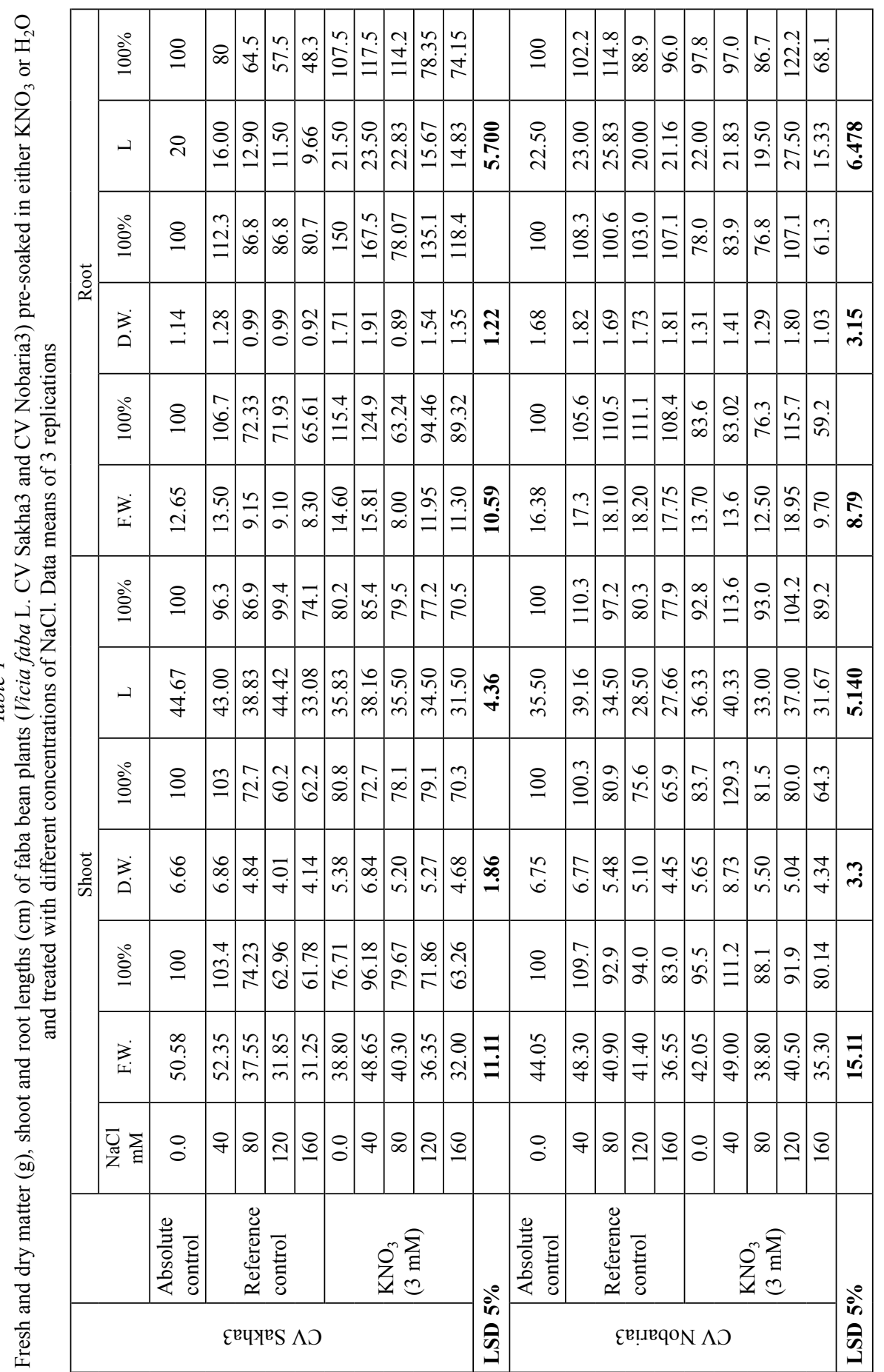




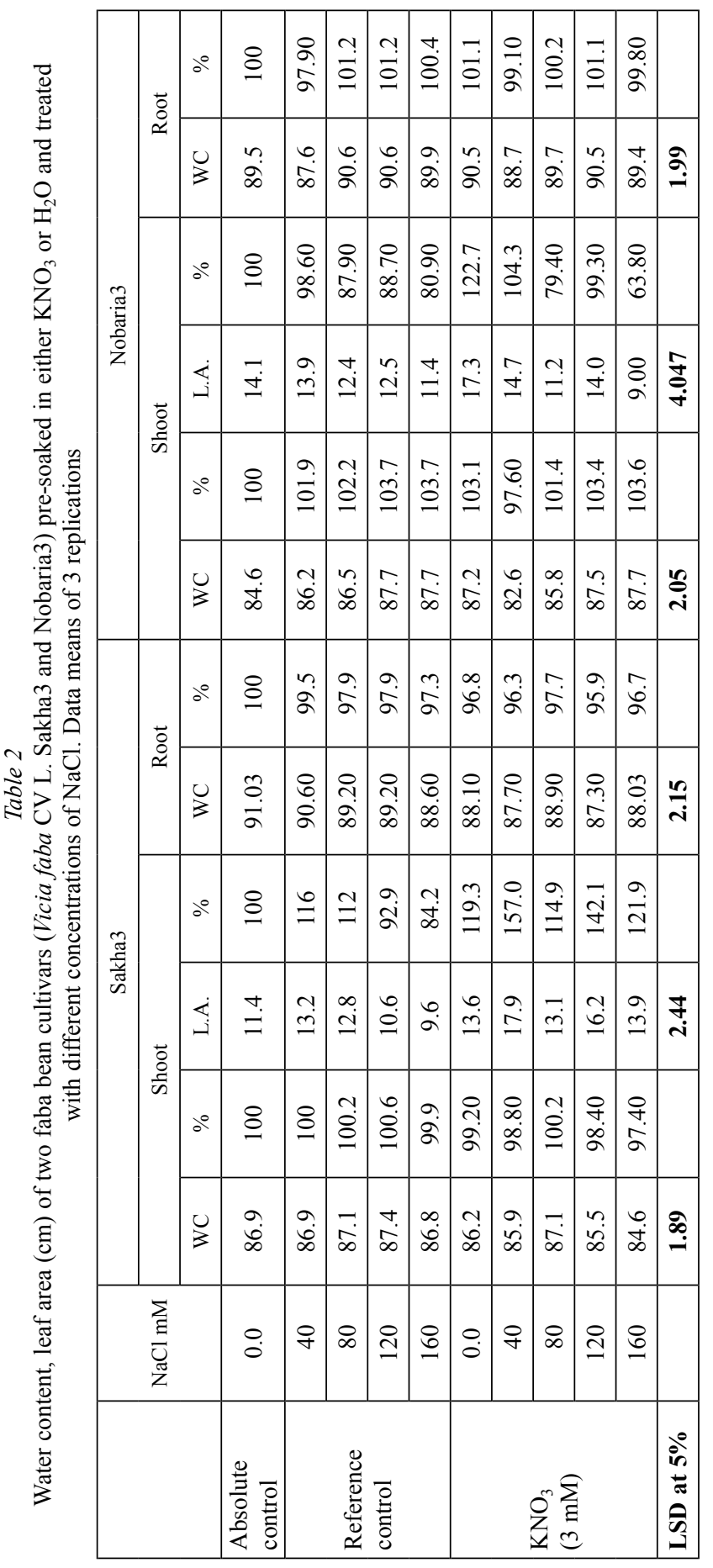




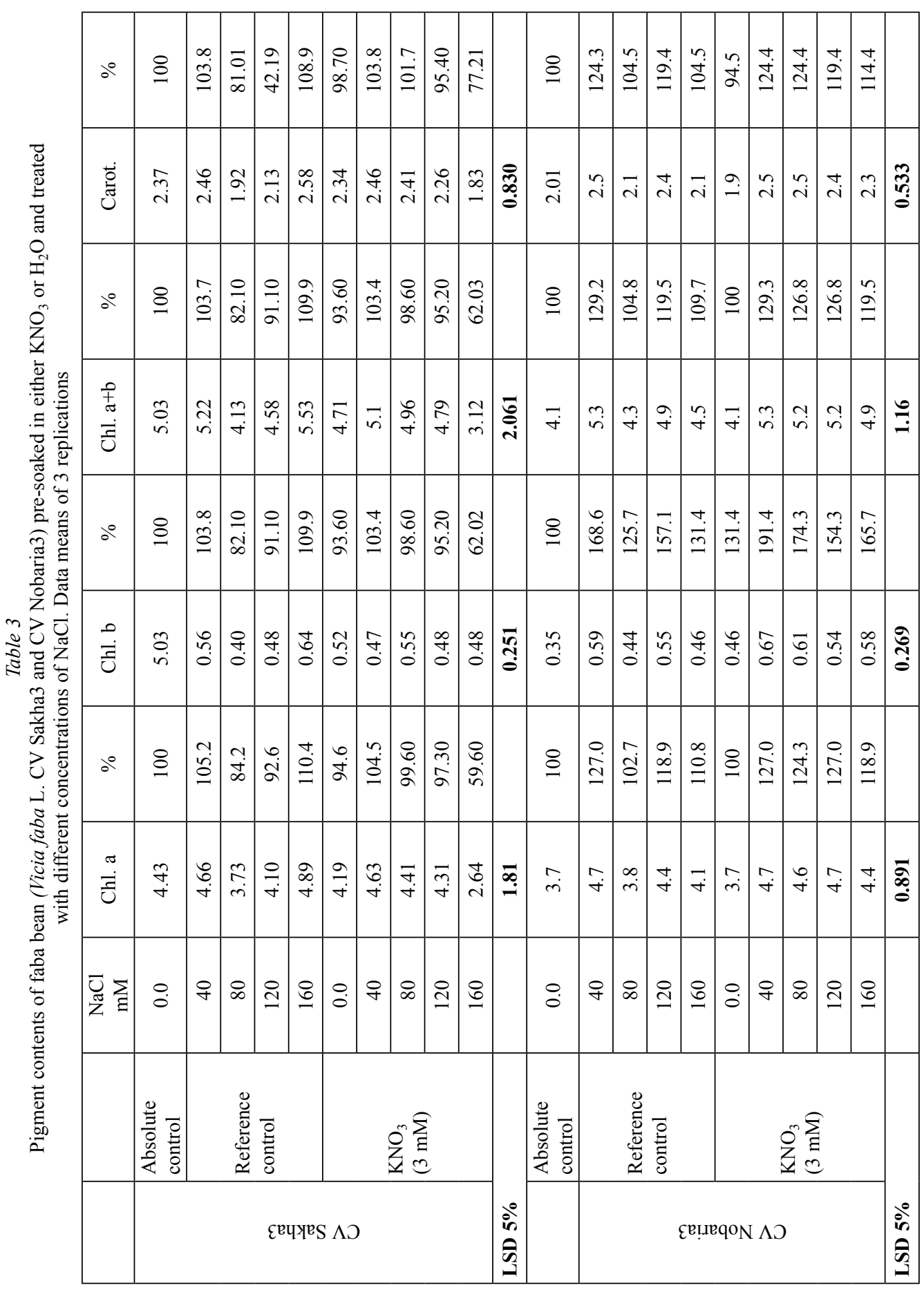




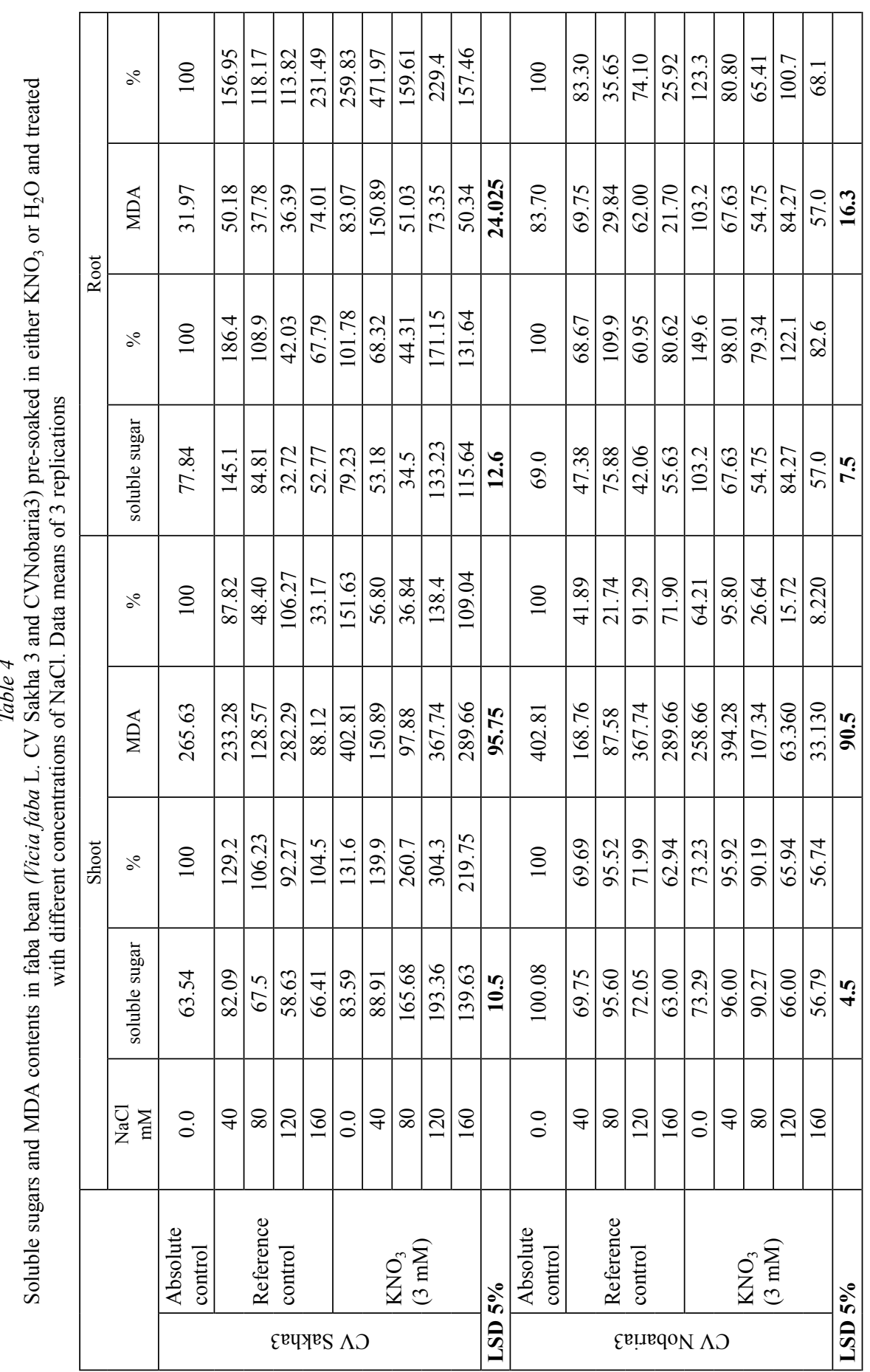




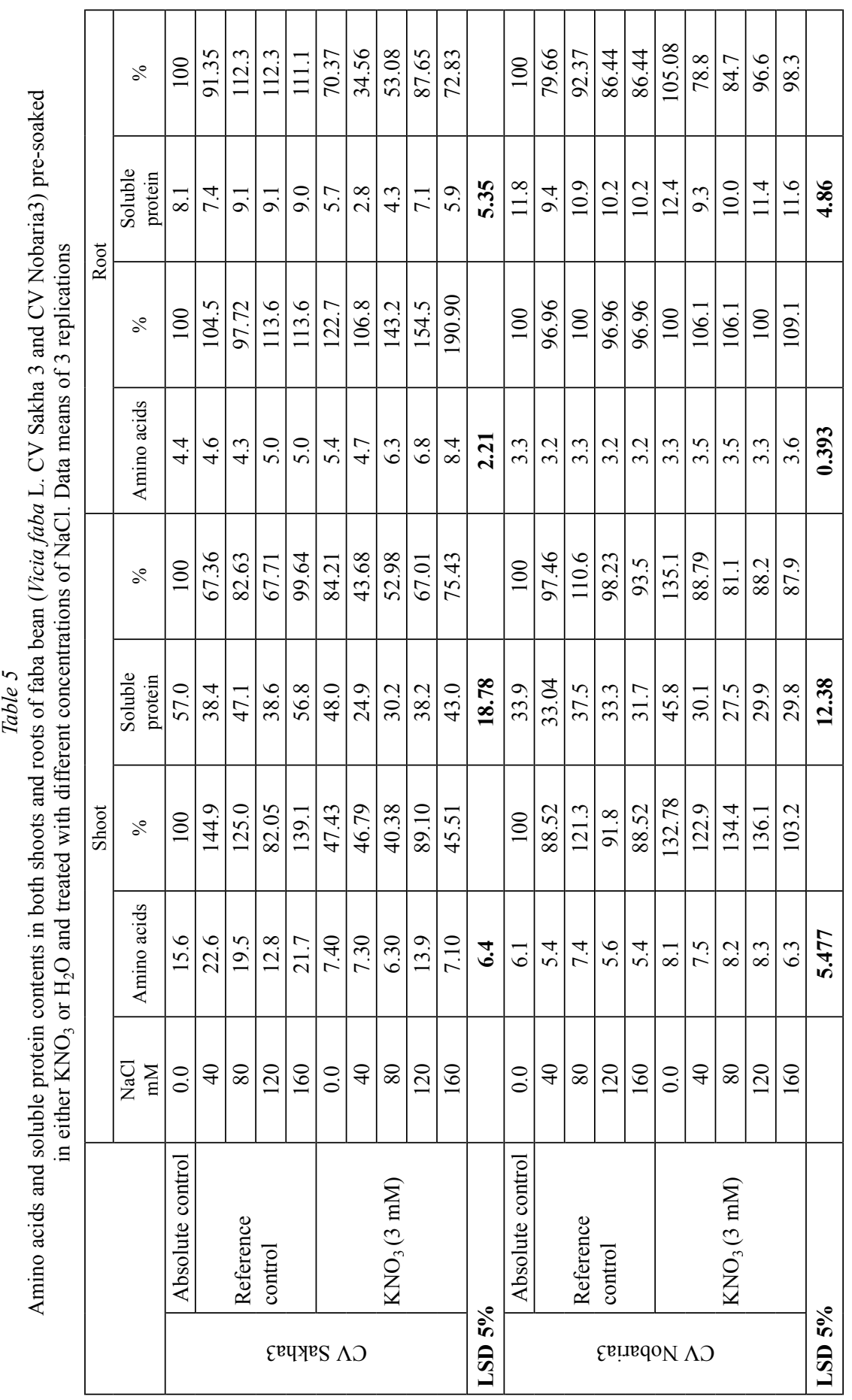

Acta Biologica Hungarica 66, 2015 
pre-soaking of both two cultivars had a positive effect on sugar accumulation in both plant organs (shoots and roots) especially in CV Sakha3. The soluble protein as well as total free amino acid contents in both cultivars are shown in Table 5. Total free amino acids were increased in shoots, but more or less unchanged in roots. However,
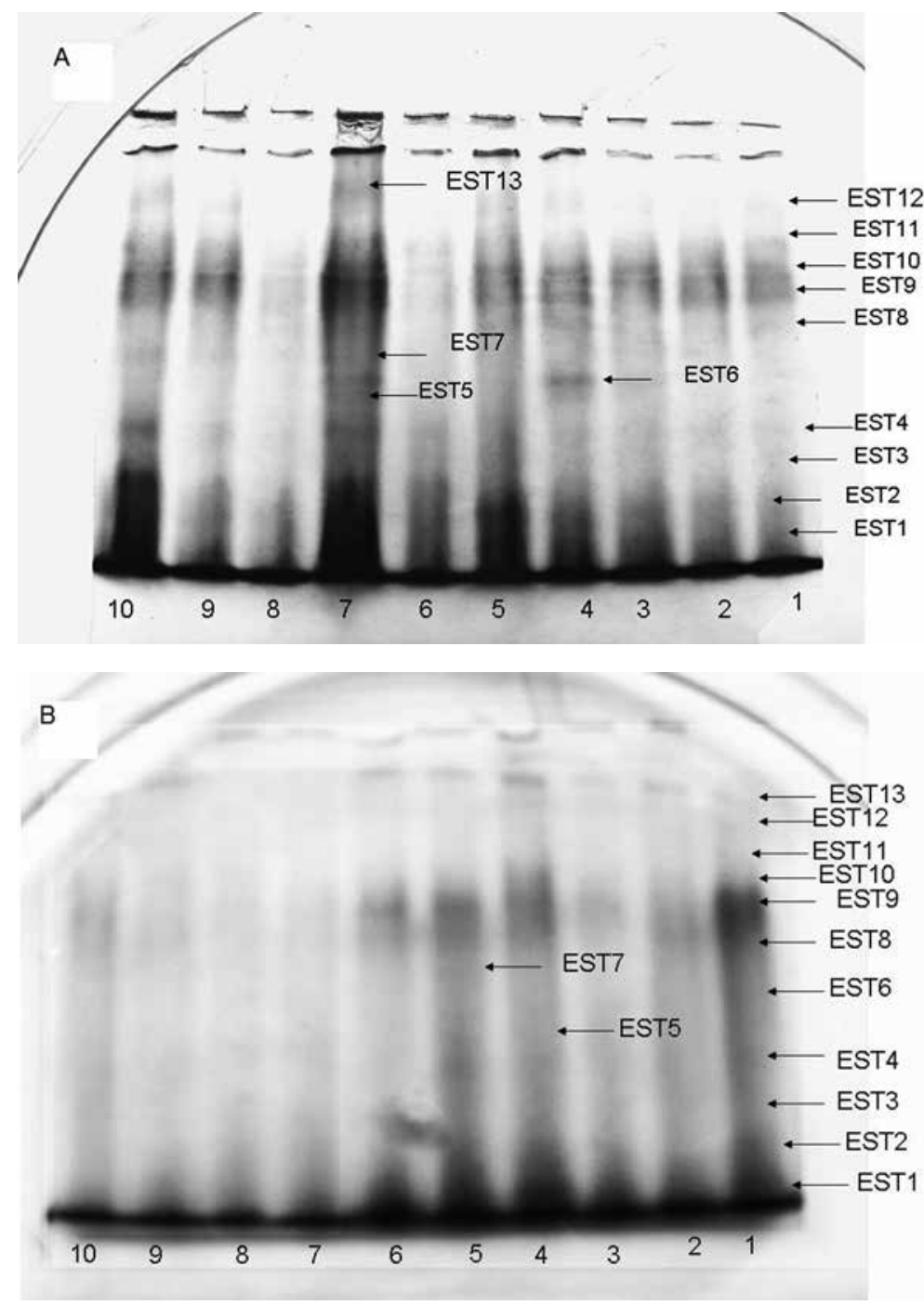

Fig. 1. Changes in esterase (EST) activity in two CV (Sakha3 and Nobaria3) Vicia faba as pre-soaked in either $\mathrm{H}_{2} \mathrm{O}$ or $\mathrm{KNO}_{3}$ and treated with different concentrations of $\mathrm{NaCl}$. A) Changes in esterase (EST) in CV Sakha 3 and B) changes (EST) in CV. Nobaria3 Lane 1 (control), Lane 2 (control $+\mathrm{KNO}_{3}$ ), Lane 3 $(40 \mathrm{mM} \mathrm{NaCl})$, Lane $4\left(40 \mathrm{mM} \mathrm{NaCl}+\mathrm{KNO}_{3}\right)$, Lane $5(80 \mathrm{mM} \mathrm{NaCl})$, Lane $6\left(80 \mathrm{mM} \mathrm{NaCl}+\mathrm{KNO}_{3}\right)$, Lane $7(120 \mathrm{mM} \mathrm{NaCl})$, Lane $8\left(120 \mathrm{mM} \mathrm{NaCl}+\mathrm{KNO}_{3}\right)$, Lane $9(160 \mathrm{mM} \mathrm{NaCl})$, Lane $10(160 \mathrm{mM}$ $\mathrm{NaCl}+\mathrm{KNO}_{3}$ ) 
the soluble protein fractions were lower than the absolute control, regardless the organ analyzed. Seed pre-soaking enhanced amino acid accumulation in both shoots and roots especially at higher levels of salt in roots of CV Nobaria3. The assessment of the esterase isozyme profiles on $7.5 \%$ native polyacrylamide gel revealed the presence of 13 isoforms in these cultivars of faba bean plants in response to $\mathrm{KNO}_{3}$ presoaking and treatments with different concentrations of $\mathrm{NaCl}$ (Fig. 1). The increase of band intensity, appearance of new bands and disappearance of esterase bands may be an indication of an increase in activity response to pre-soaking in $\mathrm{KNO}_{3}$ and treatment with different concentrations of $\mathrm{NaCl}$.

\section{DISCUSSION}

Salt stress, like many abiotic factors, reduces the ability of plants to take up water, leading to growth reduction as well as metabolic changes and disrupt nutritional balance of plants. The results of priming among species, varieties, and seeds have been variable, because of the different responses [8], suggesting that treatment conditions must be optimized for each seed, plant developmental stage, time of application and concentration. The results in Table 1 show that salinity reduced both fresh and dry weight in two broad bean cultivars (CV Sakha3 and CV Nobaria3). This reduction was more pronounced in CV Sakha3 than CV Nobaria3. The reduction reached $61.78 \%$ and $83 \%$ of absolute control at $160 \mathrm{mM} \mathrm{NaCl}$, respectively, according to fresh weight basis. Salinity had a stimulatory effect only at $40 \mathrm{mM} \mathrm{NaCl}$ in both cultivars, which produced fresh and dry matter over absolute control. Research on priming has proved that crop seeds primed with water germinated earlier, root and shoot length development started rapidly, grow more vigorously and seed length was also significantly greater than that of non-primed seeds. It could also improve the performance of crops by alleviating the effect of salts under saline soil conditions [35]. Seed pre-soaking with $\mathrm{KNO}_{3}$ resulted in fresh and dry weight enhancement in both cultivars especially at $40 \mathrm{mM} \mathrm{NaCl}$ which produced 96.18 and $111.2 \%$ of absolute control in both CV Sakha3 and CV Nobaria3, respectively, in respect to fresh weight basis. In tomato, the primed seeds with $\mathrm{KNO}_{3}$ produced seedling with better growth than the seeds primed with $\mathrm{NaCl}$ [45]. Salinity stress can cause osmotic stress and salt toxicity in plants, leading to a reduction in growth and ultimately in yield [15]. Salt stress decreased all growth and yield parameters of wheat [26]. Priming contribute to improve germination rate and seedling emergence in different plant species by increasing the expression of aquaporins and reduce the effect of salinity on the morphological parameters of plants [19].

Data presented in Table 1 indicate also that elevating salinity caused significant decreases in plant height and shoot dry weight of broad bean plants and improvement on these traits were coincided with the combined soaking with $\mathrm{KNO}_{3}$. Similar results were recorded using $\mathrm{KNO}_{3}$ with PEG [23]. The reduction in growth parameters of broad bean plants under salinity stress might be attributed to the reduction in water absorption, reduced metabolic activities due to $\mathrm{Na}+$ and $\mathrm{Cl}-$ toxicity and nutrient 
deficiency caused by ionic interference [13]. Salt stress reduced plant height and shoot dry weight, while $\mathrm{KNO}_{3}$ improved root length especially in Sakha3 cultivar. This characteristic might be used as a criteria for salt tolerance in that cultivar, thus seed germination and root length may be the best indicator of stress tolerance in plants [39].

Salinity stress is known to modify the plasma membrane lipid and protein composition of plant cells which affects water transport via aquaporins. Aquaporins are transmembrane proteins that function as channels, to facilitate and regulate the permeation of water molecules across biological membranes. Thus, it has been reported that the expression of plasma membrane aquaporin genes can be down-regulated by salt stress depending on $\mathrm{NaCl}$ concentration and tissue considered [7]. Seed presoaking in $\mathrm{KNO}_{3}$ may reactivate the expression of aquaporins during imbibition through counteracting the toxicity effect of $\mathrm{NaCl}$ and hence activate water uptake which reflected in growth enhancement. According to Argerich and Bradford [1] the occurrence of space inside primed seeds may accelerate the rate of germination by facilitating water uptake and earlier initiation of metabolism processes. Pre-soaking treatment with $\mathrm{KNO}_{3}$ had no toxic effect and not only promotes seed germination but also stimulates later growth, metabolic processes and, hence, ultimate crop yield [42].

Based on the water content of both broad bean cultivars as well as leaf area were shown in Table 2, it can be concluded that the water content were decreased by the increased salinity in the soil; seed pre-soaking with $\mathrm{KNO}_{3}$ resulted in significant increase in relative water content in both cultivars. The maximum relative water content was observed in CV Nobaria3. The leaf area in both broad bean cultivars decreased with increasing salinity. Seed pre-soaking enhanced leaf area especially in CV Sakha3 which reached $157 \%$ at $40 \mathrm{mM} \mathrm{NaCl}$ compared with absolute control. There is no doubt that each cultivars had its own mechanism for overcoming salt stress. Our results concomitant with the results of Harris et al. [23] and working with maize and using $\mathrm{KNO}_{3}$ and $\mathrm{PEG}$, who found that soaked seeds had greater plant height and leaf area and total increase in yield. Supplemented $\mathrm{K}+$ caused maintenance of leaf turgor and RWC by decreasing leaf osmotic potential under water stress conditions e.g. Lathyrus sativus L. [43].

The chlorophyll contents reflects the photosynthesis rate of plants, which are strongly influenced by environmental factors. The data of photosynthetic pigments clearly demonstrated that the biosynthesis of pigments were substantially affected by salt treatment.

The observed reduction in pigment contents might be attributed to the toxic effects of accumulated $\mathrm{NaCl}$ which inhibits pigment biosynthesis and/or enhances chlorophyll degrading enzymes [28]. However, the carotenoids which act as efficient quenchers of free radicals caused by reactive oxygen species were increased (see Table 3). The accumulated carotenoids could minimize the damaging effect of these free radicals in plants soaked with $\mathrm{KNO}_{3}$ [29]. In this respect Hamada et al. [22] found that the contents of chlorophylls and carotenoids were increased in most cases in Vicia faba leaves under salinity, however, in pea plants they remained more or less unchanged. 
The soluble sugars, soluble proteins as well as total free amino acids showed various responses in both organs (shoots and roots) of two broad bean cultivars. Soluble sugars, soluble proteins as well as total free amino acids were decreased in CV Nobaria3 and increased in CV Sakha3 with increasing salinity in the soil. Seed presoaking with $\mathrm{KNO}_{3}$ in both broad bean cultivars showed significant increase in soluble sugars especially CV Sakha3. In pigeon pea (Cajanus cajan), seeds treated with $\mathrm{KNO}_{3}$ or $\mathrm{CaCl}_{2}$ generally exhibited improvement in proteins, free amino acids, and soluble sugars content during germinating under salt stress [27]. In Vicia faba L. and sugar beet plants found that contents of (soluble sugars total, reducing, nonreducing and sucrose) were increased, but total and non-soluble carbohydrates were decreased with increasing salinity level $[15,42]$.

The soluble protein contents were decreased with increasing $\mathrm{NaCl}$ in $\mathrm{CV}$ Nobaria3, however in CV Sakha3 it shows marked increase. Munns et al. [38] reported that soluble proteins could play an important role in osmotic adjustment in water-stressed plants. Stress-induced proteins play a role in stress tolerance, which may be essential for the survival of plants under extreme stress conditions [9]. Gadallah [18] found that salinity decreased the soluble proteins content of Vicia faba L. exposed to salt stress. Under salinity the plants produce stress-responsive proteins that are involved in detoxification of ROS and thus play a role in adaptation to stress [6]. According to the plant species or cultivar the stress conditions resulted in changes in soluble protein contents due to cell structural modifications [49]. It could be concluded that the inhibitory effect of salt stress on the two broad bean cultivars was alleviated in most cases by soaking with $\mathrm{KNO}_{3}$ through enhancing the biosynthesis of free amino acids and their incorporation into proteins.

Lipid peroxidation is a widely used stress indicator of plant membranes, which is based on the malondialdehyde (MDA) production during the oxidation of polyunsaturated fatty acids under conditions of severe plant stress. The production of AOS (active oxygen species) may exceed the scavenging capacity of the antioxidant defense system as a consequence, AOS can accumulate and cause cellular damage such as lipid peroxidation or the oxidation of phospholipids and other unsaturated lipids [50]. The MDA content were reduced with increasing salinity in both organs of cultivar Nobaria3. Seed pre-soaking with $\mathrm{KNO}_{3}$ did not improve MDA in shoots but enhanced it in roots, but in most cases was still lower than the absolute control. In this respect Azooz [3] found that, salicylic acid (SA) reduces MDA content after the priming of faba bean under saline conditions and also concluded that the improvement in salinity tolerance due to the application of SA during seed priming was associated with enhanced catalase (CAT), ascorbate peroxidase (APX) and glutathione reductase (GR) activities. However CV Sakha3 cultivar showed a marked increase in MDA content in roots and slight reduction in shoots except at $120 \mathrm{mM}$, which was $106.27 \%$ of absolute control. Seed pre-soaking in $\mathrm{KNO}_{3}$ caused significant increase in MDA content in both shoots and roots. In maize (Zea mays L.) seeds primed with plant hormones also exhibited acquired abiotic stress tolerance through a more responsive antioxidative system [21]. The maintenance of low levels of MDA accumulation has 
also been associated with better resistance to drought and other environmental stresses [30].

The presence of 13 isoforms in two cultivars of faba bean plants pre-soaked with $\mathrm{KNO}_{3}$ and treated with different concentrations of $\mathrm{NaCl}$, the increase of band intensity, the appearance of new bands and disappearance of other esterase bands may be an indication of an increase in activity response to pre-soaking in $\mathrm{KNO}_{3}$ and treatment with different concentrations of $\mathrm{NaCl}$. Gigova et al. [20] reported the isoenzyme pattern and changes in the esterase activity of Synechocystis cyanobacterium under different growth conditions four clearly visible bands and eight weaker bands of esterase (EST) activity were detected by gels analysis. Broad bean cultivars contains several forms of esterase with broad range of functions, hydrolyzing ester bonds in different types of metabolites. Multiple forms of EST and their differential expression during stress conditions suggested their important role in several physiological processes [10]. Hydrolytic enzymes such as EST participate in altering cell wall [11]. The role of EST in many cases is associated with cell wall metabolism but little is known about their intracellular function. One of their most interesting functions in the cytoplasm is the metabolism of many pesticides and pollutants entering the cell [12]. Mukherjee et al. [37] reported that EST variation of Lemna minor is a potential biomarker of heavy metal pollution. Precise localization, isolation and characterization of $\mathrm{KNO}_{3}$-induced esterase isozymes are required for the understanding of their role during salt stress.

We recommend hydro-priming because it is a simple cost effective technology and the impact of it is very high in terms of enhanced yields. However halo-priming with $\mathrm{KNO}_{3}$ is effective with some salt treatments and not so with other concentrations. Also, the strategy of resistance in cultivar Sakha3 is focused on increased leaf area and root length, soluble sugars as well as amino acids. However, the other cultivar Nobaria3 maintained tolerance to stress through increasing water content, accumulation of fresh and dry matter, increased chlorophyll and carotenoid contents which had a protective role.

\section{ACKNOWLEDGEMENT}

The authors would like to thank Miss Eman Mostafa for helping in statistical analysis.

\section{REFERENCES}

1. Argerich, C. A., Bradford, K. J. (1989) The effects of priming and aging on seed vigour in tomato. J. Exp. Bot. 40, 599-607.

2. Ashraf, M., Foolad, M. R. (2005) Pre-sowing seed treatment - A shotgun approach to improve germination, plant growth, and crop yield under saline and non-saline conditions. Adv. Agron. 88, 223265.

3. Azooz, M. (2009) Salt stress mitigation by seed priming with salicylic acid in two faba bean genotypes differing in salt tolerance. Int. J. Agric. and Biol. Engin. 11, 343-350. 
4. Badour, S. S. A. (1959) Analitisch-chemische Untersuchung des Kaliummangels bei Chlorella in Vergleich mit anderen Mangel-Zustanden. Ph.D. Dissertation, Göttingen.

5. Bajehbaj, A. A. (2010) The effects of $\mathrm{NaCl}$ priming on salt tolerance in sunflower germination and seedling grown under salinity conditions. Afr. J. Biotech. 9, 1764-1770.

6. Bandehagh, A., Salekdeh, G. H., Toorchi, M. (2011) Comparative proteomic analysis of canola leaves under salinity stress'. Proteomics 11, 1965-1975.

7. Boursiac, Y., Chen, S., Luu, D. T., Sorieul, M., Dries, N., Maurel, C. (2005) Early effects of salinity on water transport in Arabidopsis roots: molecular and cellular features of aquaporin expression. Plant Physiol. 139, 790-805.

8. Bradford, K. J. (1986) Priming to improve germination under stress conditions. Hort. Sci. 21, 11051112 .

9. Chandler, P. M., Robertson, M. (1994) Gene expression regulated by abscisic acid and its relation to stress tolerance'. Annu. Rev. Plant Physiol. Plant mol. Biol. 45, 113-141.

10. Coppens, L., Dewitte, D. (1990) Esterase and peroxidase zymograms from barley (Hordeum vulgare L.) callus as a biochemical marker system of embryogenesis and organogenesis. Plant Science 67, 97-105.

11. Cosgrove, D. J. (2001) Wall structure and wall loosening. A look backwards and forwards. Plant Physiol. 125, 131-134.

12. Cummins, I., Burnet, M., Edwards, R. (2001) Biochemical characterization of esterases active in hydrolysing xenobiotics in wheat and competing weeds. Physiol. Plant. 113, 477-485.

13. De Lacerda, C. F., Cambraia, J., Oliva, M. A., Ruiz, H. A. (2003) Osmotic adjustment in roots and leaves of two sorghum genotypes under $\mathrm{NaCl}$ stress. Braz. J. Plant Physiol. 15, 113-118.

14. Demir Kaya, M., Okcu, G., Atak, M., Cikili, Y., Kolsarici, O. (2006) Seed treatment to overcome salt and drought stress during germination in sunflower (Helianthus. annuus L.). J. Eur. Agron. 24, 291295 .

15. Ebrahim, M. K. (2005) Amelioration of sucrose-metabolism and yield changes, in storage roots of $\mathrm{NaCl}$-stressed sugar beet, by ascorbic acid. Agrochimica, XLIX (3-4), 93-103.

16. Fales, F. W. (1951) The assimilation and degradation of carbohydrates by yeast cells. J. Biol. Chem. 193, 113-124.

17. FAO (2008) FAO Land and Plant Nutrition Management Service. http://www.fao.org/agl/agll/spush.

18. Gadallah, M. A. (1999) Effects of proline and glycinebetaine on Vicia faba in response to salt stress. Biol. Plant 42, 249-257.

19. Gao, Y. P., Young, L., Bonham-Smith, P., Gusta, L. V. (1999) Characterization and expression of plasma and tonoplast membrane aquaporins in primed seed of Brassica napus during germination under stress conditions. Plant Mol. Biol. 40, 635-644.

20. Gigova, L., Gacheva, G., Ivanova, N., Pilarski, P. ( 2012) Effects of temperature on synechocystis sp. r10 (cyanoprokaryota) at two irradiance levels. i. effect on growth, biochemical composition and defense enzyme activities. Gen. Plant Physiol. V2, 24-37.

21. Guan, Y. J., Hu, J., Wang, X. J., Shao, C. X. (2009) Seed priming with chitosan improves maize germination and seedling growth in relation to physiological changes under low temperature stress. J. Zhejiang Univ-Sci. B 10, 427-433.

22. Hamada, A. M., El-Enany, A. E. (1994) Effect of $\mathrm{NaCl}$ salinity on growth, pigment and mineral element contents, and gas exchange of broad bean and pea plants. Biol. Plant. 36, 75-81.

23. Harris, D., Rashid, A., Miraj, G., Arif, M., Shah, H. (2007) On-farm' seed priming with zinc sulphate solution - A cost-effective way to increase the maize yields of resource poor farmers. Field Crops Res. 102, 119-127.

24. Heath, R. L., Packer, L. (1968) Photoperoxidation in isolated chloroplast. 1. Kinetics and stiochiometry of fatty acid peroxidation. Arch. Bioch. Biophys. 125, 189-198.

25. Hus, J. L., Sung, J. M. (1997) Antioxidant role of glutatnione associated with accelerated agina and hydration of triploid Watermelon seeds. Physiol Plant. 100, 967-974. 
26. Hussein, M. M., Abd El-Rheem, K. M., Khaled, S. M., Youssef, R. A. (2011) Growth and nutrients status of wheat as affected by ascorbic acid and water salinity. Nature and Science 9, 64-69.

27. Jyotsna, V., Srivastava, A. K. (1998) Physiological basis of salt stress resistance in pigeon pea (Cajanuscajan L.)-II. Pre-sowing seed soaking treatment in regulating early seedling metabolism during seed germination. Plant Physiol. Biochem. 25, 89-94.

28. Khan, M. A., Ahmed, M. Z., Hameed, A. (2006) Effect of sea salt and L-ascorbic acid on the seed germination of halophytes. J. Arid Environ. 67, 535-540.

29. Khosravinejad, H. F. R., Farboondia, T. (2008) Effect of salinity on photosynthetic pigments, respiration and water content in barley varieties. Pak. J. Biol. Sci. 11, 2438-2442.

30. Lima, A. L. S., DaMatta, F. M., Pinheiro, H. A., Totola, M. R., Loureiro, M. E. (2002) Photochemical responses and oxidative stress in two clones of Coffea canephora under water deficit conditions. Environ. Exp. Bot. 47, 239-247.

31. Lowery, O. H., Rosebrough, N. H., Farr, A. L., Randall, R. J. (1951) Protein measurements with the folin phenol reagent. J. Biol. Chem. 193, 291-297.

32. McDonald, M. B. (1999) Seed deterioration: physiology, repair and assessment. Seed Sci. Technol. 27 , 177-237.

33. Metzner, H., Rau, H., Senger, H. (1965) Untersuchungen zur synchronisierbarkareit einzelener-pigment. Mangel Mutanten von Chlorella. Planta 65, 186-194.

34. Moeinrad, H. (2008) The relationship between some physiological traits and salt tolerance in pistachio genotypes. Desert. 13, 129-136.

35. Mohammadi, G. R., Dezfuli, M. P. M., Sharifzadeh, F. (2008) Seed invigoration techniques to improve germination and early growth of inbred line of maize under salinity and drought stress. Gen. Appl. Plant Physiol. 34, 215-226.

36. Moore, S., Stein, W. (1948) Partition chromatography of amino acids on starch. Annual. N.Y. Acad Sci. 49, 265-278.

37. Mukherjee, S., Bhattacharyya, P., Duttagupta, A. K. (2004) Heavy metal levels and esterase variations between metal-exposed and unexposed duckweed Lemna minor: field and laboratory studies. Environ Interactions 30, 811-814.

38. Munns, R., Brady, C. J., Barlow, E. W. (1979) Solute accumulation in the apex and leaves of wheat during water stress. Aust. Plant Physiol. 6, 379-389.

39. OlfaBaatour, R., Kaddour, W., Aidi Wannes, M., Lachaal Marzouk, B. (2009) Salt effects on the growth, mineral nutrition, essential oil yield and composition of marjoram (Origanum majorana). Acta Physiol. Plant. 10, 0374-4.

40. Qadir, M., Tubeileh, A., Akhtar, J., Larbi, A., Minhas, P. S., Khan, M. A. (2008) Productivity enhancement of salt-affected environments through crop diversification. Land Degradation Develop. 19, 429-453.

41. Roy, N. K., Srivastava, A. K. (2000) Adverse effect of salt stress conditions on chlorophyll content in wheat (Triticum aestivum L.) leaves and its amelioration through pre-soaking treatments. Indian $J$. Agric. Sci. 70, 777-778.

42. Sallam, H. A. (1999) Effect of some seed-soaking treatments on growth and chemical components of faba bean plants under saline conditions. Ann. Agric. Sci. (Cairo). 44, 159-171.

43. Sarkar, R. K., Malik, G. C. (2001) Effect of foliar spray of potassium nitrate and calcium nitrate on grass pea (Lathyrus sativus L.) grown in rice fallows. Lathyrus Lathyrithm Newsletter 2, 47-48.

44. Schlegel, H. G. (1956) The recovery of organic acid by Chlorella in the light. Planta 47, 510-526.

45. Takhti, S., Shekafandeh, A. (2012) Effect of different seed priming on germination rate and seedling growth of Ziziphus Spina-Christi. Adv. Environ. Biol. 6, 159-164.

46. Tanksley, S. D., Orton, T. J. (eds) (1983) Isoenzymes in plant genetics and breeding. Part A, Elsevier Amsterdam, New York

47. Wang, Z. Q., Yuan, Y. Z., Ou, J. Q., Lin, Q. H., Zhang, C. F. (2007) Glutamine synthetase and glutamate dehydrogenase contribute differentially to proline accumulation in leaves of wheat (Triticum 
aestivum) seedlings exposed to different salinity. Original Research Article. J. of Plant Physiol. 164, 695-701.

48. Wiersma, T. V., Bailey, T. B. (1975) Estimation of leaflet, trifoliate and total leaf area of soybean Agron. J. 176, 26-30.

49. Wimmer, M. A., Muhling, K. H., Lauchli, A. (2003) The interaction between salinity and boron toxicity affects the sub cellular distribution of ions and proteins in wheat leaves. Plant Cell Environ. 26, 1267-1274.

50. Zhou, R., Zhao, H. (2004) Seasonal pattern of antioxidant enzyme system in the roots of perennial forage grasses grown in alpine habitat, related to freezing tolerance. Physiol. Plant. 121, 399-408. 